\title{
Int'I Symposium on Materials Science Applications of Ion Beam Techniques Covers Rapidly Evolving Research Topics
}

An International Symposium on Materials Science Applications of Ion Beam Techniques was held at Seeheim, Germany, September 9-12, 1996. It also incorporated the First Australian-German Workshop on Ion Beam Analysis.

The program of talks and posters reflected substantial progress and innovation in a range of topics including basic ion-solid interactions, ion-beam modification of metals and ceramics and polymers, implantation in semiconductors, and ionbeam analysis.

Some of the fast evolving research topics covered included nanostructures (both surface and bulk) produced by ion implantation; shear flow and surface rippling or smoothing; defect gettering and the role of multiple-energy implant processing of semiconductors; detailed modeling of ion cascade evolution and thermal spike structure; low-energy plasma treatment of surfaces; control of polymer tailoring by implantation; microbeam studies of radiation-induced single-upset events in silicon devices; and high depth resolution (monolayer) ion-beam analysis using high efficiency spectrometers.

The title of "Best Poster" was awarded to M. Jentschel and K.H. Heinig (Research Center, Rossendorf, Dresden) and H.G. Borner (Institute Laue-Langevin, Grenoble), for their study of Atomic Collision Cascades in Ionic Compounds. They reported studies of collision processes in crystalline solids at low energies ( $1 \mathrm{eV}$ to $1 \mathrm{keV}$ ), based on Doppler-broadened gamma line shapes from neutron capture. Their comparison with molecular dynamics simulations leads to new information about classical interatomic potentials.

The conference was organized by Adam G. Balogh (Technical University Darmstadt), with K. Bethge and J.D. Meyer (University of Frankfurt) and G. Walter (Darmstadt), and sponsored by those institutions together with Deutsche Forschungsgemeinschaft (DFG), Bundesministerium für Bildung und Forschung (BMBF), Hessisches Ministerium für Wissenschaft und Kunst (HMWK), and Gesellschaft für Schwerionenforschung (GSI).

JOHN E.E. BAGLIN

\section{INTERNATIONAL UNION OF MATERIALS RESEARCH SOCIETIES}

\section{Okinaga Symposium to Precede IUMRS-ICA-97}

The Third Okinaga Symposium on Materials Science and Engineering Serving Society, September 13-15, 1997, in Makuhari, Chiba, Japan, is sponsored by the Okinaga Foundation, the U.S. Army and Navy, and Chon International. The symposium encourages collaboration between international science and engineering communities for the benefit of humankind. Consisting of a series of invited talks by experts on materials, this event is a satellite symposium of IUMRSICA-97 (International Union of Materials Research Societies--International Conference in Asia) and is held just before it. Among the areas the Symposium will cover are employment (creating new materials and processes), environment (waste management), and health (biomaterials). Proceedings from Okinaga Symposium will be published.

Tentative invited speakers include R.P.H. Chang, Northwestern University; M.C. Chon, Chon International; R. Chujo, Teikyo University of Science and Technology; R. de Marco, Naval Research Chemistry Division; M. Doyama, Teikyo University of Science \& Technology; K. Ito, JEOL; D. Kolar, University of Ljubrijana; K. Kugimiya, Matsushita Electric Co.; R.A. Laudise, Bell Laboratories; O.C.C. Lin, Industrial Technology Research Institute; J.A. Miller, DuPont; M. Mitomo, NIRIM; K. Niwa, Fujitsu; C.N.R. Rao, Indian Institute of Science; R. Roy, The Pennsylvania State University; S. Somiya, Teikyo University of Science \& Technology; K. Sugita, Nippon Steel Co.; Y. Tanaka, Nippon Steel Co.; T. Weber, U.S. National Science Foundation; N. Yamamoto, NGK Insulators; R. Yamamoto, The University of Tokyo; N. Yamazaki, Kochi University; and D.S. Yan, Shanghai Institute of Ceramics.

Send correspondence to Professor Shigeyuki Somiya, Teikyo University of Science \& Technology, 3-4-7 Seijo, Setayaya, Tokyo 157, Japan; 81-3-3417-2866 or 81-55463-4411 ext. 2700; or fax 81-3-3415-6619.

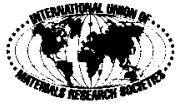

\begin{tabular}{|c|c|}
\hline Advertisers in This Issue & \\
\hline High Voltage Engineering & \\
\hline Huntington Laboratories & \\
\hline Ion Tech, Inc. & \\
\hline inside back cover & sent to: \\
\hline Parke Mathematical Laboratories & MRS Bulletin \\
\hline Virginia Semiconductor, Inc. & 9800 McKnight Road \\
\hline Vóltaix, Inc. & Pittsburgh, PA 15237-6006 \\
\hline $\begin{array}{l}\text { For free information about the products and services offered in this issue, fill out and mail the } \\
\text { Reader Service Card, or FAX it to (312) 922-3165. }\end{array}$ & E-mail: bulletin@mrs.org \\
\hline
\end{tabular}

